sputum examinations. It is certainly incidental in some cases: one of the patients developed the disease five years after discharge from hospital, and has been symptomless until quite recently. Segregation of patients undergoing operation for bronchiectasis from those suffering from open tuberculosis is obviously essential. The cases in which the patients are worse after operation are the results of recovery following suppurative pneumonitis, one of them being a case of bilateral disease. Persistent bronchial fistula is rare, and some of these four cases will probably close in the course of time. The remainder of the end-results do not require explanation.

\section{Total Pneumonectomy}

A few observations may here be made about pneumonectomy for bronchiectasis and infected cystic disease. That the patients who recover are able to carry on a normal existence is now proved beyond doubt. Further, that compensation takes place through hypertrophy of the remaining lung is generally accepted, and, as regards function, it can be proved by the steady improvement which results in the vital capacity over the ensuing eighteen months. Necessarily the mortality will be higher than that of a more limited operation, but will almost entirely depend upon the operative difficulties of removal-that is, the density of the adhesions. In this group there were thirtythree cases-thirteen in which the right lung has been removed and twenty in which a left pneumonectomy was performed. Seven patients died in hospital, three cases being left-sided and four right-sided, giving a mortality of 21 per cent. Six cases were done in two stages, the lower lobe being removed first and the upper lobe later for residual disease, the periods between stages varying from three weeks to nine months. In twenty-seven the operation was carried out in one stage. One patient died from miliary tuberculosis some time after discharge from hospital.

The analysis of deaths in this group is instructive. One died from pericarditis and one from bronchopneumonia of low virulence (two months) and do not need comment. Another patient, who was quite reasonably well, was given a blood transfusion on the third day ; anuria followed, and death resulted about four days later. Three patients died from the effects of embolism-two from cerebral abscess on the fourth and twelfth day respectively, and one from air embolism on the second day. The other death occurred from a severe gangrenous infection of the pleural cavity. (It is noteworthy that the operation wound remained healed throughout.)

As to late results, nineteen patients are symptomless and working. Four have a bronchial fistula, which will probably heal in due course. Two patients remain in hospital; one who was operated upon several weeks ago is convalescent, the other is recovering well (operation more recent). In all cases of lobectomy and pneumonectomy, unless a thoracoplasty has been previously performed, deformity is negligible.

\section{Conclusion}

No one who has seen the satisfactory results which can be obtained by surgical measures could doubt that the operations of lobectomy and pneumonectomy provide the greatest advance in the treatment of bronchiectasis, and I hope I have persuaded you that it is a procedure which is now associated with a mortality that should be negligible if the disease is treated in its early stages, and which has a high proportion of curative results.

\section{REFERENCES}

Alexander, J. (1933). Surg. Gynec. Obstet., 56, 658.

Bethune N. (1935), J. thorac, Surg., 4, 251.

Brunn, H. (1929). Arch. Surg., 18, 490.

Churchill, E. D. (1937). J. thorac. Surg., 6, 286.

Edwards, A. Tudor, and Thomas, C. Price (1934). Brit. J. Surg. 22,310 .

Findlay, L., and Graham, S. (1927). Arch. Dis. Childh., 2, 71.

- (1931). Ibid., 6, 1.

Gowar, F. S. (1939). Unpubiished Hunterian Lecture.

Graham, E. A. (1925). Arch. Surg., 10,392.

- Singer, J. J., and Ba!lon, H. С. (1935). Surgery of the Chest p. 657. Henry Kimpton, London.

Lilienthal, H. (1935). Quoted by Graham, Singer, and Ballon in Surgery of the Chest, p. 656

McCordoch, H. A. (1932). Proc. exp. Biol. Med.. N.Y., 29, 1288.

McDowell, H. (1930). Trans. med. Soc. Lond., 53, 65.

Roberts, J. E. H., and Nelson, H. P. (1933). Brit. J. Surg., 21, 277

Roles, F. C., and Todd, G. S. (1933). British Medical Journal, $2,639$.

Shenstone, N. S., and Janes, R. M. (1932). Canad. med. Ass. J., 27,138

Sicard, J. A., and Forestier, J. (1922). Bull. Mém. Soc. méd. Hôp. Paris, 46, 463 .

\section{A CASE OF PEllagra}

The pathological Changes in the SPINAL CORD

BY

J. G. GREENFIELD, M.D., F.R.C.P.

Pathologist, the National Hospital, Queen Square AND

J. MacDONALD HOLMES, M.D., M.R.C.P.

Physician, the Staffordshire General Infirmary

(With Special Plate)

Pellagra is a rare disease in Great Britain, particularly in children, the published cases up to 1934 being only 131 in number (Stannus and Gibson, 1934). The only cases in children were those described by Box (1914), Hutchison and Paterson (1923), and Parsons (1929). The endemic incidence of pellagra in other countries, especially those where maize is a staple article of diet, has masked the significance of sporadic cases such as the one to be described, and it is possible that many of them pass unrecognized. These sporadic cases are often described as "secondary" pellagra, but there seems to be no reason, on either clinical or pathological grounds, why they should be placed in a separate category from "endemic" pellagra. The changes in medical thought concerning the disease from the time of its description by Gaspar Casal in 1735 have been well reviewed by Flinker (1935), and it would be difficult after reading this review to think of any other condition in which the aetiology has been the subject of so much speculation. The theory that a diet consisting largely of maize was the main factor in the production of pellagra was the predominant one for many years, and no doubt this was responsible for the infrequent recognition of the disease in countries where maize is not a staple food.

\section{Cause of Pellagra}

It is now generally recognized that maize plays no specific part in the causation of pellagra. The classical dietetic experiments of Goldberger and his associates (1926) proved that maize only produces pellagra because it is deficient in a substance closely related to vitamin $B_{3}$, which they called the "pellagra-preventing factor." Later work has shown that vitamin $\mathbf{B}_{z}$ is a complex consisting of at least three factors, and that the " pellagra-preventing 
factor" is one of these, existing in food as the relatively simple compound nicotinic acid or its amide (Harris, 1937 ; Spies, Cooper, and Blankenhorn, 1938 ; Spies, 1938). In a review of the theories of causation of pellagra Stannus (1936) says:

"A study of the disease from a wide angle suggests a new hypothesis - namely, that pellagra is one among a number of conditions which are severally due to a failure in production of 'principles' by the interaction of 'extrinsic factor' in the food with 'intrinsic factor' in the gastric juice. In pellagra one or other or both of these factors may be involved-an extrinsic factor due to deficiencies in the diet, an intrinsic factor due to non-secretion consequent upon gastritis."

Levy Simpson (1935) made a similar suggestion, drawing attention to the similarity between the gastro-intestinal disorders associated with megalocytic hyperchromic anaemias and those associated with " secondary" pellagra. Stannus suggests that gastritis may be a common factor in the production of a megalocytic anaemia, a microcytic anaemia, subacute combined degeneration, and pellagra. He postulates that the gastritis may affect with unequal incidence the secretion of a number of "intrinsic" factors necessary to the normal metabolism of the body, and that the specific disorder present depends upon the intrinsic factor whose secretion is most affected. It is possible on this theory to explain the occasional occurrence of pellagra in cases where intestinal absorption is defective by assuming that the product of interaction of the extrinsic food factor and the intrinsic factor is excreted unabsorbed. A case of this kind was recently seen by one of us (J. MacD. H.) by kind permission of Dr. A. V. Campbell. A farm labourer aged 35 was admitted to hospital for investigation of a chronic diarrhoea of some months' duration. He was found to have a mild pigmented dermatitis of pellagrous appearance on his face, hands, and forearms. His mentality was sluggish, and there was absence of the knee- and ankle-jerks with slight impairment of vibration sense in the legs. There was a histamine-refractory achlorhydria, and bacteriological and serological investigation showed that the diarrhoea was due to infection with $B$. dysenteriae Shiga. After a week's treatment with nicotinic acid the rash was much improved, and it disappeared after a fortnight. The patient left hospital without much improvement in his dysentery having taken place, and he has not been seen since.

\section{Symptoms}

The clinical neurological symptoms of pellagra, apart from mental changes, have been described by some writers as being similar to those of subacute combined degeneration, but in a review of 100 cases seen in the Bukowina district Flinker (1934) found that the neurological symptoms and signs were very variable and widely distributed, and that those suggestive of subacute combined degeneration were ill defined and of infrequent occurrence. According to Flinker mental symptoms varying from dullness to severe dementia are common in those cases in which the nervous system is involved. The most frequent affection of the motor system takes the form of a spastic paresis, but it is uncommon for the paresis to be as severe as the reflex changes would suggest. It is usually more marked in the legs than in the arms. Tremors are common, and their character often suggests an involvement of the pallido-striatal system. The involvement of the sensory system is rarely severe, usually consisting of paraesthesiae and numbness. Occasionally there may be signs of peripheral nerve involvement, such as muscular wasting and loss of tendon reflexes. The cranial nerves are usually spared, but sometimes pupillary changes and nystagmus are seen. The signs vary from day to day in a manner suggestive of disseminated sclerosis.

The case to be described showed signs of extensive involvement of the nervous system, including the spinal cord, but neither the clinical features nor the histological findings resembled those in subacute combined degeneration. The only obvious gastro-intestinal disorder was a gastritis associated with a histamine-refractory achlorhydria. There was no abnormality in the diet which could give rise to a vitamin deficiency, and it seems reasonable to suppose that some deficiency in the gastric juice was responsible for the development of the pellagra.

The exact relationship of deficient gastric secretion to the origin of pellagra is not yet known. Petri, Wanscher, and E. and H. P. Stubbe-Teglbjaerg (1937) have reviewed the evidence in the literature in favour of a gastrogenic aetiology of the disease. They quote six cases of their own treated with ventriculin in support of their view that the gastric secretion possesses a specific anti-pellagra function, and conclude that a functional disorder of the digestive tract is the most important aetiological factor in all cases of pellagra. They also suggest that the designations " primary" and " secondary" pellagra should no longer be used. In the light of our present knowledge the following theory seems to be the most acceptablenamely, that pellagra is due to a deficiency of an extrinsic factor in the diet (nicotinic acid) or to a failure of assimilation of this factor, if it be present, owing to gastrointestinal disease.

\section{Case Report}

A boy aged 5 was sent into the Staffordshire General Infirmary by the late Dr. A. E. Hodder on July 4, 1937. He was perfectly healthy until about May, 1936, when he developed a scaly rash and pigmentation of a coppery-red colour on his face, hands, and knees. The rash almost disappeared about September, 1936, nothing being left but a slight reddening of the affected parts. No other symptoms were present at this time, and the child was well until June, 1937, when the rash again appeared on the parts exposed to light. This time the scaly erythema was much more severe, and there was blistering and ulceration of the backs of the hands and the face. Soon after the appearance of the erythema the child's mother noticed a deterioration in his intelligence. He was previously very bright and intelligent, but rapidly became listless and apathetic. He would cry very readily, sometimes for no obvious reason. His speech became very slurred and almost unintelligible, and his mother thinks that he was not aware of what was going on around him or of what was said to him, as he often took no notice, but moaned and cried out for long periods at a time. Up to three days before admission he was very restless and could not sleep, but during the last three days he had been drowsy and the involuntary crying had become less frequent. Soon after the failure of intelligence was noticed the boy began to stumble easily and " rapidly went off his feet." $\mathrm{He}$ "would tremble all over" when attempts were made to put him on his feet, and he was by then unable to stand at all.

Personal and Family History.-The boy was born near Stafford and had never been more than a few miles away from home. His parents have lived near Stafford all their lives, but the father was in the Army for two years during the war, part of which time was spent in India. There were five other children in the family-three girls, aged 17, 14, and 7 years, and two other boys, aged 13 and 11 . These children were all examined, and they appeared to be perfectly healthy. All the children, including the patient, were fed upon an ordinary mixed diet, which included plenty of fresh vegetables, milk, and butter, with perhaps an excess of the latter, as the parents were farmers. The patient showed no idiosyncrasy to any kind of food.

Previous Illnesses:-These were chicken-pox in September, 1936, and whooping-cough in March, 1937. Soon after the 
latter disease a skin lesion, which was thought to be ringworm, appeared on the lower lumbar region, and there was slight ulceration. The scar of this was still to be seen, and there was a small scabbed area.

\section{EXAMINATION}

The child lay curled up in bed and did not like to be turned towards the light. He was drowsy and very sluggish in his response to questions. He occasionally attempted to reply, but his speech was unintelligible and frequently punctuated by low cries, rather like a "meningitic cry." $\mathrm{He}$ could not stand unless supported, but was able to sit up without assistance.

Skin Lesions.-The skin was excessively dry over the whole body. There was a symmetrically distributed coppery-red erythema on the face, ears, and upper part of the chest and neck (Plate, Fig. 1). The hands, forearms, and knees were also affected, as were the scrotum and perineum to a slight extent. There was oedema and thickening of the skin and extensive desquamation. On the face and the backs of the hands there was blister formation and ulceration. There was some reddening and scarring over the lower lumbar region, in a roughly circular area about the size of a half-crown. Bleeding fissures were present at the angles of the mouth, and the tongue was red, dry, and slightly swollen. The buccal mucosa was also red and dry. The hair was dry and thin, and appeared to have fallen out in places.

No abnormality was found in the chest and heart. The blood pressure was $102 / 75$.

Central Nervous System.--The pupils were widely dilated, but reacted to light and accommodation. The optic fundi and disks appeared normal. Slight ill-sustained nystagmoid jerks were observed on movement of the eyes in all directions. There was definite photophobia, and the child quickly curled up and turned his face away from a bright light.

Motor System.-Both arms were markedly spastic, and movements were accompanied by a coarse tremor which was increased in intensity when definite movements, such as conveying food to the mouth, were attempted. Motor power was extremely weak, and objects were held only with difficulty. Both legs were weak and spastic. The child was unable to stand unless supported. He staggered and fell in all directions when support was withdrawn. Some of this appeared to be due to loss of position sense apart from motor weakness. The same coarse tremor was present in the legs as in the arms.

Reflexes.-The biceps, triceps, supinator, and pronator jerks were all brisk on both sides. The right and left upper abdominal reflexes were present but sluggish; the lower ones were both absent. Both knee- and ankle-jerks were exaggerated, and there were bilateral extensor plantar responses.

The sensory system could not be examined, but there appeared to be some loss of pain sensibility in the hands and feet, as pinprick did not elicit much response unless applied very strongly.

\section{PATHOLOGICAL INVESTIGATIONS}

There was a complete achlorhydria, with no response to histamine injection. The blood count showed: red cells, 4,450,000 per c.mm. ; haemoglobin, 79 per cent. ; colour index, 0.88 . The leucocytes numbered 11,000 per c.mm.: polymorphs, 68.75 per cent.; lymphocytes, 24.5 per cent.; monocytes, 4.5 per cent. ; eosinophils, 2.0 per cent.; and basophils, 0.25 per cent. The red cells showed slight anisocytosis but no poikilocytosis. The halometer reading was 7.5. Examination of the cerebrospinal fluid revealed a pressure of $120 \mathrm{~mm}$. The fluid was slightly bloodstained, due to the child struggling. Cytology was not possible owing to blood being present. The protein content was $70 \mathrm{mg}$. per $100 \mathrm{c.cm}$. The Wassermann reaction was negative in blood and fluid. The blood calcium amounted to $10.3 \mathrm{mg}$. per $100 \mathrm{c} . \mathrm{cm}$. The urine contained no abnormal constituents. Its specific gravity was 1030 , and its chlorides $114 \mathrm{mg}$. per $100 \mathrm{c.cm}$.

On admission the stools were loose and semi-formed, and pale yellow in colour. Microscopical examination showed no pus, blood, or mucus, but there was an excess of free fatty acid crystals, and also much undigested foodstuff. CharcotLeyden crystals were present. There was no excess of soaps, and no protozoa or cysts were seen. On culture, only $B$. coli was recovered. A quantitative estimation of the faecal fat content was done later, but treatment had been continued for a fortnight at this time. The results were as follows: total fat, 20 per cent. by weight of dried faeces; free fatty acid, 9 per cent.; neutral fat, 4 per cent.; combined fatty acids, 7 per cent. These figures are within normal limits.

The blood cholesterol amounted to $189 \mathrm{mg}$. per $100 \mathrm{c.cm}$. In a test of glucose tolerance the fasting blood sugar was 0.1 per cent. Half an hour after 25 grammes of glucose were given it was 0.125 per cent.; at one hour, 0.15 per cent.; at one and a half hours, 0.143 per cent.; and at two hours, 0.1 per cent. Radiographs of the long bones and skull showed no rarefaction or other abnormality. A follow-through radiographic examination of the stomach and alimentary tract revealed no abnormality or delay in passage of the barium meal.

\section{TREATMENT AND PROGRESS}

On July 5, 1937, a daily dosage of 6 drachms of fresh brewer's yeast was begun, in equal portions of two drachms three times a day, together with acid. hydrochlor. dil. 35 minims. On July 15 and July $22,4 \mathrm{c} . \mathrm{cm}$. of campolon was given intramuscularly. After about one week's stay in hospital a considerable improvement in the rash was noticed. The ulcers on the hands and face were almost healed, and erythema was much less. The drowsiness had disappeared. The child took notice when he was spoken to and was able to ask for food, but he was still unable to stand without support. At the end of the second week in hospital the coppery-red discoloration of the skin had completely disappeared, the ulceration was entirely healed, and all that could be seen on the affected areas of the skin was a café-au-lait coloration and some dry desquamation. The child could raise himself to his feet and stand without support, but he was unable to walk without assistance because of the spastic condition of his legs. His mental state was much better and his speech more distinct, so that occasionally he could be understood, but he could not co-operate well enough for an examination of his sensory system to be made. There was no improvement in sphincter control.

On July 26 the child developed measles in an epidemic which affected several children in the ward, and he died of bronchopneumonia two days later. The measles rash was very intense on the sites of the previous pellagra rash and only slight elsewhere.

\section{Post-mortem Findings}

A post-mortem examination was made twelve hours after death. The respiratory organs showed extensive bilateral bronchopneumonia, with much frothy muco-pus in the air passages. The lungs were otherwise healthy. The heart muscle was rather pale. All the chambers contained agonal clot. The aortic cusp of the mitral valve showed a roughly circular patch of subintimal lipoid deposit on its undersurface, about $\frac{3}{4} \mathrm{~cm}$. in diameter. The oesophagus was normal in appearance. The whole of the gastric mucosa presented a finely nodular appearance-the so-called état mamelonné of chronic gastritis. There was no evidence of ulceration. The small intestines appeared to be rather thin-walled, but otherwise there were no naked-eye changes. The large intestine was also rather thin-walled, but otherwise normal. The spleen, suprarenals, pancreas, and urinary bladder were normal. The kidneys showed slight cloudy swelling, and the liver slight toxic changes. The brain and spinal cord were removed intact for histological examination: no naked-eye changes were seen.

\section{Report on the Histological Examination}

Sections were stained from various parts of the cortex, brain stem, and spinal cord by the usual stains for nervous tissue (Plate, Figs. 2, 3, and 4). The most striking abnormalities were seen by the Nissl and Marchi methods, the Weigert-Pal and Scharlach $R$ methods showing little abnor- 
mality. With the Nissl method chromatolytic changes of varying degrees of intensity were seen in many nerve cells. The anterior horn cells of the spinal cord and the cells of the cranial motor nerves were most affected. Some of them showed the typical appearances of central chromatolysis. In others the eccentric or subcapsular position of the nucleus and the breaking up of the Nissl substance were similar, but the angular outline of the cells was preserved or even exaggerated. Cells of this kind were most abundant in the lumbar enlargement, and they were not seen elsewhere in the spinal cord. The cells of the intermedio-lateral tract appeared normal. In those of Clarke's column the nucleus was often more eccentric than normal, but the appearances were not very unusual. In the nuclei of the cranial nerves and in the motor cortex a large proportion of the nerve cells had undergone chromatolysis. The Betz cells were particularly affected. Fewer chromatolytic cells were seen in the frontal and occipital cortex, and the hippocampal formations were remarkably free from abnormal cells. In the basal ganglia a small proportion of the large nerve cells were similarly affected, whereas the cells of the substantia nigra and nucleus ruber appeared healthy.

In the cerebellar cortex the Purkinje and granule cells had their normal number and appearance. In the dentate nucleus, on the other hand, rather less than half the cells showed a subcapsular position of the nucleus. The cells of the inferior olive looked quite normal. The Gros-Bielschowsky method applied to the cerebellar cortex showed normal baskets round the Purkinje cells and no torpedoes on the axones of the latter.

With the Marchi-Busch method degeneration was very definite in the column of Goll, and was present to a less degree in the direct and indirect spino-cerebellar tracts, and, to a slight degree also, in the pyramidal tracts, both crossed and uncrossed. The entering posterior root fibres were affected at all levels but most severely in the lumbar region, and here also some degeneration of the anterior root fibres was seen. A root from the cauda equina central to the ganglion examined by this method also showed degeneration of a few fibres, but the majority were normal. With Scharlach $\mathrm{R}$ the cord at first sight looked normal, but when examined carefully with higher powers a few balls of myelin or early katabolic products of myelin were seen. No red staining indicating further degrees of myelin katabolism was seen. No lipoid was present in the nerve cells of the spinal cord. With the Nissl and haematoxylin-van Gieson methods a few glial stars could be seen in the posterior and lateral columns of the cord. No degenerative or other changes could be observed in the blood vessels of the central nervous system. The mesenteric ganglion examined showed some excess of small cells, but the nerve cells appeared normal.

In the heart the nerves looked healthy. Unfortunately there were no ganglion cells present in the section examined. Of the other organs examined the skin showed an excess of cells in the dermis. These appeared to be chiefly fibroblasts. No lymphocytes or plasma cells could be made out. In the stomach there was evidence of subacute gastritis with much infiltration with small round cells, both diffusely and in more aggregated masses. Among these, eosinophil leucocytes were fairly numerous. There was no apparent loss of oxyntic cells.

\section{Comment}

The condition in the nervous system was evidently one of neuronal degeneration in which somatic efferent neurones, both upper and lower, and the neurones which have their cell station in the dorsal root ganglia, were chiefly affected. There was also some degeneration in the spino-cerebellar tracts. The basal ganglia were severely involved, as was also the motor cortex. In other parts of the cortex the condition was less intense, but there were enough chromatolytic nerve cells in them to explain the mental deterioration from which the patient suffered. There was nothing in the spinal cord resembling the changes seen in subacute combined degeneration. The myelin sheaths were not swollen, and no fenestrated areas were seen in the cord similar to those present in the latter disease. Rather the degeneration seen by the Marchi-Busch method indicated degeneration of the nerve fibres as a whole, and, at least so far as the anterior roots were concerned, was associated with severe chromatolytic changes in the cell body. This type of degeneration was, in fact, the only one seen throughout the nervous system.

The degeneration in the motor cortex was of the type which was called by Adolf Meyer "central neuritis" and which has been found by various authors to be the most common change in the cerebral cortex in pellagra (Beyer, 1932 ; Langworthy, 1931). Pearson (1928) says: "In pellagra every case shows this microscopic picture," and refers to nine cases observed by himself; all showing central neuritis.

There is singularly little evidence to be found in the literature on pellagra as to the character of the spinal lesions, although their general topography is well known. Nageotte and Riche (1907) interpret Tuczek's reports as indicating a lesion of the root fibres after they enter the cord, which, however, differs from that seen in tabes dorsalis in sometimes affecting the fibres most severely near their termination in the nuclei of the dorsal columns. Wilson (1914), Pentschew (1928), and, more recently, Guillain, Bertrand, Mollaret, and Lereboullet (1934) have allied them to the lesions seen in subacute combined degeneration of the cord. The case examined by the latter authors was unusual in that spinal symptoms were severe from the beginning, whereas no dementia was noticed at any time.

In Langworthy's case (1931) the symptoms were, as in the case here reported, of only a few weeks' duration, and the lesions in the spinal cord were recent. They resemble those in our case except that the dorsal columns were reported to be intact, although degenerative changes were seen in the neurones of the posterior root ganglia. The degeneration in the cord was systematized, affecting the pyramidal and spino-cerebellar tracts, and, on the evidence of the photomicrographs, was not of the lacunar type seen in subacute combined degeneration. The case reported by Zimmerman, Cohen, and Gildea (1934) was complicated by alcoholism, but the changes in the nervous system were very similar to those in the present case. They are inclined to agree with Batten, who examined the cord in Sandwith's case, that the degeneration in the dorsal columns is due to lesions of the entering root fibres. In all except one of Pentschew's cases the lesion in the cord consisted of demyelinated scars of irregular and asymmetrical arrangement in the posterior columns and on the margins of the antero-lateral columns. In only one case was there symmetrical and systematized degeneration of the columns of Goll.

From this brief survey of the literature it would appear that the most common lesions in the spinal cord in pellagra consist of symmetrical degeneration of the dorsal columns, especially that of Goll, and the spino-cerebellar and pyramidal tracts. In most cases the afferent tracts are more affected than the efferent, though in occasional cases no lesion of the dorsal columns has been found. Pentschew's cases appear to be unique in the irregularity and focal nature of the spinal lesions.

In most of the reports from which definite evidence can be gleaned, either from the description or from the illustrations, as to the histological details of the lesion, it appears to differ from that of subacute combined degeneration in two respects: it does not present the lacunar appearance due to gross distension of the myelin sheaths which is characteristic of subacute combined degeneration; 
nor do the early lesions in the dorsal columns usually affect the central area on each side as they do in the latter disease (Michell Clarke, 1904; Greenfield and O'Flynn, 1933). In the cases reported by Wilson (1914) and White and Hadfield (1927), however, the early lesions were in this area. In the present case the disease is seen in its early stages and appears as a degeneration of the nerve fibre, either as a whole or most intense towards its termination, as suggested by Nageotte and Riche. It was most marked in, although not strictly limited to, the long ascending and descending tracts in the cord.

While the type of disease in this case corresponds to that found in the majority of recorded cases, there appears to be considerable variation in the incidence of the disease on neuronal systems. For example, the posterior columns may be spared and the Purkinje cells of the cerebellar cortex degenerated. Again, in what seems to be a large proportion of all cases of pellagra the spinal cord is unaffected. It would appear that in certain epidemics, or in certain countries, spinal disease is a more common accompaniment of pellagra than in others. If this is so it would suggest that the variations in the incidence of the disease on different parts of the nervous system are due to differences in its causation. This hypothesis is in agreement with the results of animal experiments in vitamin starvation in which minimal differences in diet appear to produce great differences in the degree and incidence of the degeneration in the nervous system.

\section{Summary}

The current theories regarding the causation of pellagra are discussed and the literature surveyed.

The clinical neurological symptoms of the condition are described.

A case of pellagra occurring in Great Britain is reported: the pathological changes taking place in the spinal cord are reviewed.

The suggestion is submitted that pellagra may be due to the deficiency of an extrinsic factor in the diet (nicotinic acid) or to a failure to assimilate this factor.

\section{REFERENCES}

Beyer, A. (1932). Arch. f. Psychiat., 98, 294.

Box, C. R. (1914). British Medical Journal, 2, 397.

Clarke, J. M. (1904). Brain, 27, 441.

Flinker, R. (1934). Z. ges. Neurol. Psychiat.. 151, 642.

- (1935). Ergebn. inn. Med., 49, 522

Goldberger, J. (1926). Medicine, 5, 79.

Greenfield, J. G., and O'Flynn, E. (1933). Lancet, 2, 62.

Guillain, G., Bertrand, I., Mollaret, P., and Lereboullet, J. (1934). Bull. Mém. Soc. méd. Hôp. Paris, 50, 650

Harris, L. J. (1937). Nature, 140, 1070.

Hutchison, R., and Paterson, D. (1923). British Medical Journal, 2, 646.

Langworthy, O. R. (1931). Brain, 54, 291.

Nageotte, J., and Riche, A. (1907). In Cornil and Ranvier's Manuel d'Histologie Pathologique, 3, Paris.

Parsons, L. G. (1929). Arch. Dis. Childh., 4, 246.

Pearson, G. H. J. (1928). Arch. Neurol. Psychiat.. Chicago, 20, 366.

Pentschew, A. (1928). Z. ges. Neurol. Psychiat., 118, 17.

Petri, S., Wanscher, O., and Stubbe-Teglbjaerg, E. and H. P. (1937). Acta med. scand.. 93, 450.

Simpson, S. Levy (1935). Quart. J. Med., n.s. 4, 191.

Spies, T. D. (1938). Lancet. 1, 252.

- Aring, C. D.. Gelperin, J., and Bean, W. B. (1938). Amer. J. med. Sci., 196, 461.

Cooper, C., and Blankenhorn, M. A. (1938). J. Amer. med. Ass., 110, 622

Stannus, H. S. (1936). Trop. Dis. Bull., 33, 885.

and Gibson, C. R. (1934). Quart. J. Med., n.s. 3, 211.

White, E. B., and Hadfield, G. (1927). Bristol med.-chir. J., 44, 31.

Wilson, S. A. K. (1914). Proc. roy. Soc. Med., 7 (Neurol. Sec.), 31

Zimmerman, H. M., Cohen, L. H., and Gildea, E. F. (1934). Arch. Neurol. Psychiat., Chicago, 31, 290.

\section{METASTATIC RENAL INFECTION}

BY

THOMAS MOORE, M.S., F.R.C.S.

Chief Assistant to a Surgical Unit and Urological Registrar, Manchester Roval Infirmary

\section{(With Special Plate)}

It is becoming increasingly evident that many minor local infections are often complicated by a transient or even prolonged bacteriaemia. The organisms usually escape the local defencès in such small numbers or are of such reduced virulence that the reticulo-endothelial system is able to engulf and destroy them without any metastatic lesions developing. Nevertheless on occasion the invaders are of sterner stuff and cause further inflammatory mischief in other parts of the body. Blood cultures have often been shown to be positive in many local infections, particularly following surgical or accidental trauma. Okell and Elliott (1935) have shown experimentally how slight trauma may drive virulent streptococci from infected tooth sockets into the blood stream. There is no evidence of the bacteriaemia produced by enthusiastic squeezing of a furuncle or following ill-judged incision, but I have no doubt of its occurrence.

The kidney is a common site of these metastatic lesions. The primary focus is usually a boil or carbuncle. In some cases a whitlow, infected abrasion or wound, tonsillitis, nasal and respiratory infections, or even dental sepsis may be the primary cause. The multiple abscesses which may occur in the kidneys in the pyaemia resulting from such conditions as osteomyelitis, septic phlebitis, and ulcerative endocarditis fall, of course, into a separate well-defined group which it is not the purpose of this paper to discuss.

The common organism is the Staphylococcus aureus or albus, although "streptococci and other organisms are occasionally found. It is interesting to speculate why cutaneous infection is often the forerunner of acute osteomyelitis in children and of metastatic renal or perirenal infections in adults. The small capillaries at the growing end of a long bone on slight trauma may give rise to a haematoma, which acts as the nidus for staphylococci circulating in the blood stream. In adults, growth being finished, the metaphyses are not so vulnerable. The kidney is designed as an excretory filter, and might be expected to catch circulating organisms. Trauma may be responsible for localization, as many clinical records of cases of metastatic renal infection following injury and the experimental work of Schnitzler (1913) show. The view that in adults some back pressure on the kidneys from early urethral obstruction, usually of prostatic origin, is a factor in localization would appear to be without foundation. Metastatic renal lesions are commonest in young adults, in whom there is no suggestion of urinary obstruction. Brady (1932) described a case of a carbuncle in a kidney the ureter of which was the seat of a definite stricture. It is curious that staphylococci so commonly lodge in the kidney, and it has been suggested that because they are able to break down urea they find a suitable environment there.

Another interesting feature is the time interval. Quite often the original lesion has been healed for many months before the metastatic lesion appears. Perhaps the clinical healing of an inflammatory disease is no guarantee that all the organisms have been eliminated or destroyed. Many may lie dormant in the tissues for some time, later to become active and spread by the blood stream. The 
J. G. GREENFIELD AND J. MACDONALD HOLMES: A CASE OF PELlaGRA: THE PATHOLOGICAL CHANGES IN THE SPINAL CORD

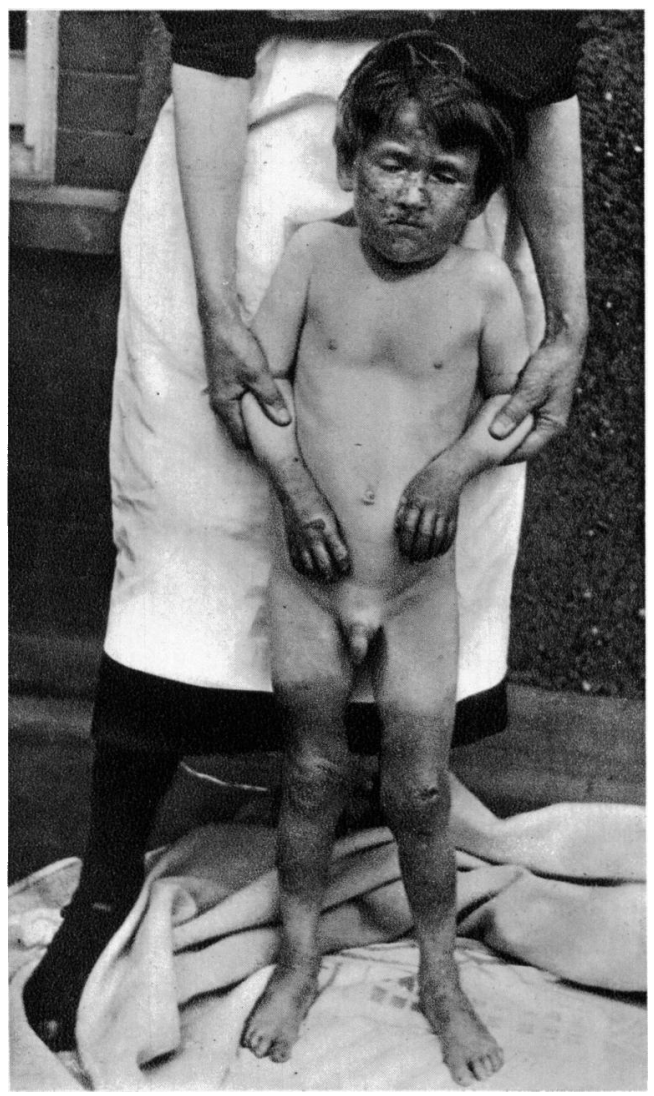

Fia. 1.-Photograph of the patient showing skin lesions.

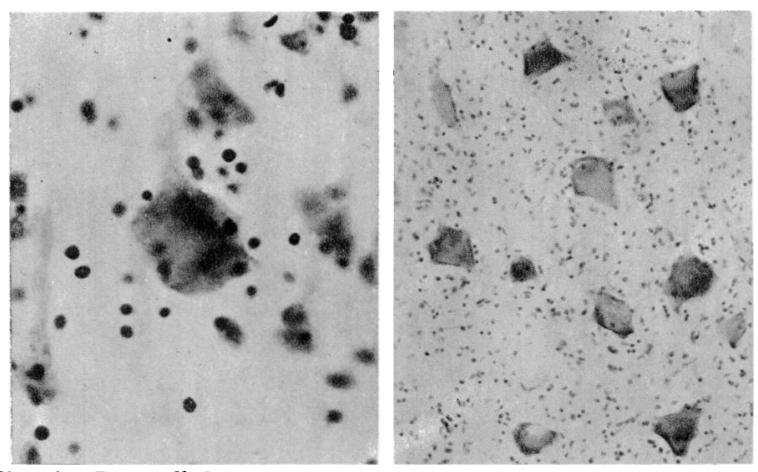

Fic. 2.-Betz cell from the motor cortex, showing Intense chroma-
tolysis (Meyer's central neuritis).

Fia. 3.- A group of motor cells from the anterior horn of the lumbar cord.

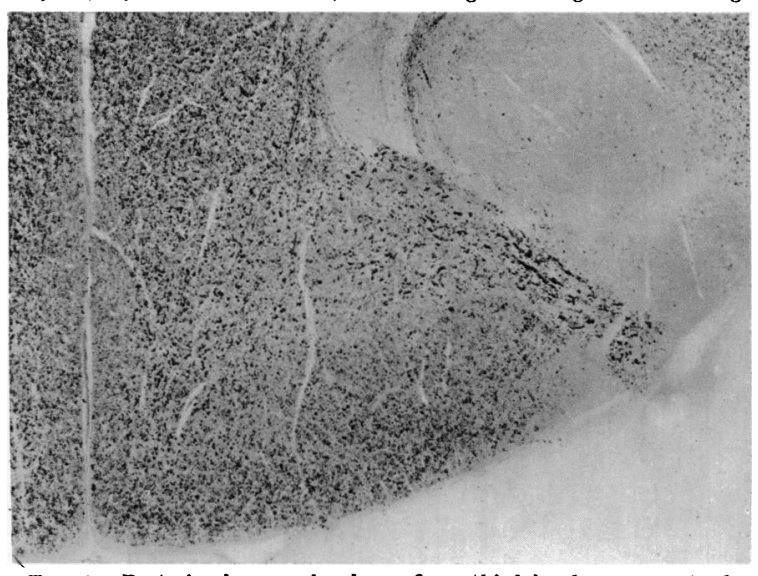

Fig. 4.-Posterior horn and column from third lumbar segment of the spinal cord, showing degeneration of entering root fibres and scattered degenerated fibres in the posterior columns.

THOMAS MOORE : METASTATIC RENAL INFECTION

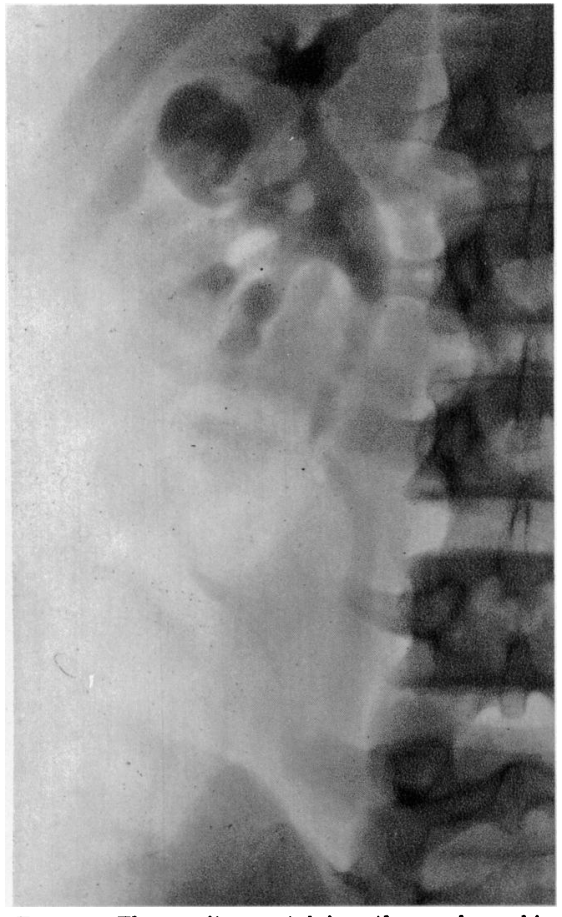

Fia. 1.-The cavity containing the pyelographic medium can be seen communicating with the middle

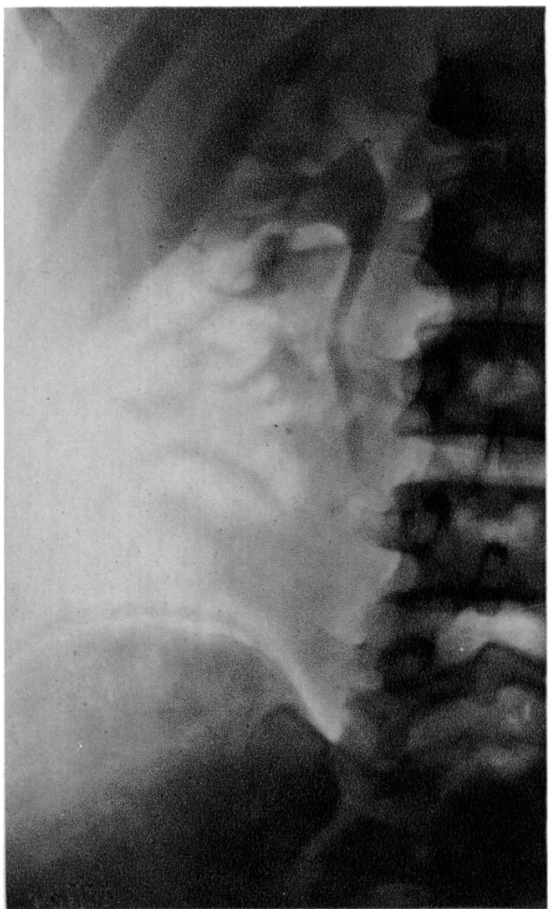

Fio. 2.-The cavity is seen to be much smaller.

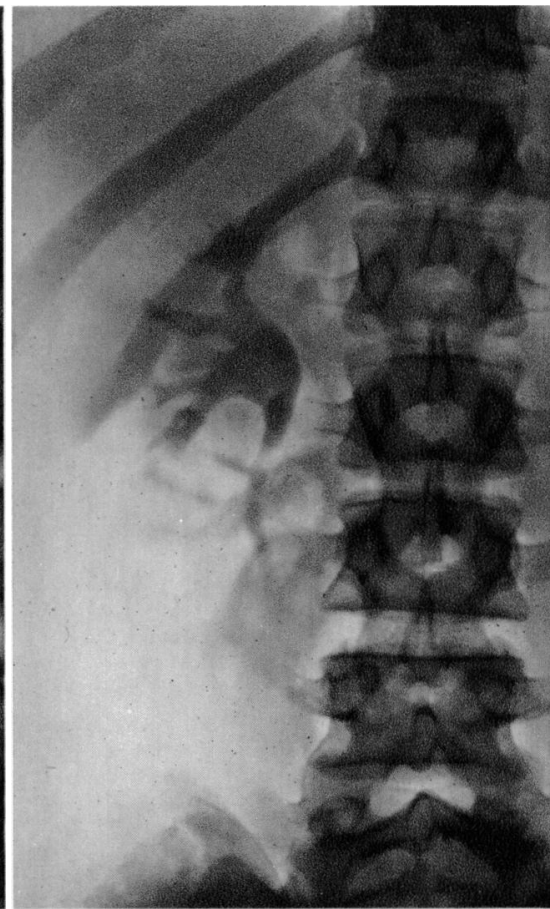

Fic. 3. - The cavity has disappeared. The kidney has returned to normal. calix. 